\title{
Prognostic value of gasping for short and long outcomes during out-of-hospital cardiac arrest: an updated systematic review and meta-analysis
}

\author{
Qiang Zhang, Bo Liu, Zhijiang Qi and Chunsheng Li* (B)
}

\begin{abstract}
Objective: We systematically reviewed the literature to investigate whether gasping could predict short and long outcomes in patients with out of hospital cardiac arrest (OHCA).

Methods: PubMed, Embase, and Cochrane Library were searched for observational studies regarding the prognostic effect of gasping on short and long outcomes in adults with OHCA. The primary outcome was return of spontaneous circulation (ROSC). The secondary outcomes were favorable neurological outcome at discharge or at 30 days after cardiac arrest; long term ( $\geq 6$ months) survival; initial shockable rhythm. The Mantel-Haenszel method with random-effects model was used to calculate pooled relative risks (RRs) and 95\% confidence intervals (Cls).

Results: Five studies (six cohorts) were included in the final analysis. In the pooled analysis, gasping was not only associated with a significant increase in ROSC (RR, 1.87; 95\% Cl, 1.64-2.13; $\left.1^{2}=70 \%\right)$, but also a high likelihood of favorable neurological outcomes (RR, 3.79; 95\% Cl, 1.86-7.73), long-term survival (RR, 3.46; 95\% Cl, 1.70-7.07), and initial shockable rhythm (RR, 2.25; 95\% Cl, 2.05-2.48).

Conclusions: Current evidence indicates that gasping can predict short and long outcomes in patients with OHCA. In addition, gasping is associated with a high likelihood of initial shockable rhythm, which may contribute to positive outcomes.
\end{abstract}

Keywords: Gasping, Cardiac arrest;meta

\section{Introduction}

Gasping or agonal respirations are abnormal breathing pattern,which are common in the first few minutes after cardiac arrest (CA) [1, 2]. In the 2015 guidelines for CA, gasping has also been highlighted and it was recommended that Emergency Medical Service (EMS) dispatchers should pay more attention to it [3].

It has been reported that the presence of gasping is associated with an increased return of spontaneous circulation (ROSC) and survival to hospital discharge $[4,5]$. A meta-analysis was conducted by Zhao et al. to evaluate the impact of gasping on short term outcome.

\footnotetext{
* Correspondence: Icscyyy@163.com

Department of Emergency Medicine, Beijing Chao-Yang Hospital,Capital Medical University, 8\# Worker's Stadium South Road, Chao-Yang District, Beijing 100020, China
}

(C) The Author(s). 2018 Open Access This article is distributed under the terms of the Creative Commons Attribution 4.0 International License (http://creativecommons.org/licenses/by/4.0/), which permits unrestricted use, distribution, and reproduction in any medium, provided you give appropriate credit to the original author(s) and the source, provide a link to the Creative Commons license, and indicate if changes were made. The Creative Commons Public Domain Dedication waiver (http://creativecommons.org/publicdomain/zero/1.0/) applies to the data made available in this article, unless otherwise stated.

They found that patients who were gasping were 3.5 times more likely to survive to discharge than those without gasping [four studies, five cohorts, $95 \%$ confidence interval (CI) $3.0-4.1 ; P<0.01]$ and that the presence of gasping predicts ROSC [relative risk (RR) 2.2 ; $95 \%$ CI $1.7-$ 2.8; $P=0.02$ [ [6]. However, in this study, the result of ROSC was obtained from a single study, and they did not report the impact of gasping on long term prognosis. After this meta-analysis, several studies regarding gasping in patients with OHCA were published. Wolfskeil et al. founded that a higher gasping rate and deeper negative pressures, but not the presence of gasping, were associated with ROSC [7]. Moreover, there were no meta-analysis conducted to determine whether gasping is associated with an initial shockable rhythm, which can affect CA outcomes. Therefore, to provide the latest and most 
convincing evidence, we systematically reviewed the current available literature to investigate whether gasping was associated with ROSC. The secondary outcomes were to evaluate whether gasping could predict (1) favorable neurological outcomes at discharge or at 30 days after CA and (2) long-term survival ( $\geq 6$ months), and (3) whether gasping is associated with an initial shockable rhythm.

\section{Materials and methods}

\section{Literature search and selection criteria}

PubMed, Embase, and Cochrane Library were used to search for records reporting the prognostic effect of gasping on ROSC and long term outcomes in patients with CA. No language restriction was imposed. The last search was run on July 30, 2018. Two independent investigators carried out the initial search, deleted duplicate records, screened the titles and abstracts for relevance, and identified articles that were excluded or required further assessment. The reference lists of relevant studies were also screened in order to identify further studies of interest.

The following search strategy was used for MEDLINE, and was modified to suit other databases.

1. Cardiac arrest

2. CA

3. Cardiopulmonary resuscitation

4. $\mathrm{CPR}$

5. or/1-4

6. Gasping

7. Agonal breathing

8. Agonal respiration

9. or $/ 6-8$

10. 5 and 9

Studies meeting the following criteria were included: (1) population: adult patients with OHCA; (2) intervention: gasping; (3) comparison: no gasping; (4) outcome: ROSC, favorable neurological outcome at discharge or at 30 days, long term survival ( $\geq 6$ months), rate of initial shockable rhythm; and (5) design:observational studies (prospective or retrospective cohort studies).

\section{Data extraction and quality assessment}

Data extraction was performed by Z.Q and confirmed independently by L. B. The following information was extracted from each study: first author, year of publication, country, study design, patient characteristics, number of patients enrolled, intervention, and outcome data. When the same patients were reported in several publications, we retained only the largest study to avoid duplication of information. Discrepancies were resolved by discussion with third the investigators (CS.L). Two investigators (Q.Z and ZJ.Q) independently utilized the Newcastle-Ottawa Scale (NOS) [8] to assess the risk of bias for observational studies.

\section{Statistical analysis}

RevMan 5.3 (Nordic Cochrane Centre) was used to perform the statistical analyses. Differences were expressed as RR with $95 \% \mathrm{CI}$. The fixed-effect model were usd when heterogeneity was not present $\left(\mathrm{PQ} \geq 0.1\right.$ or $\mathrm{I}^{2} \leq$ $50 \%$ ), otherwise random-effect model was used (PQ $<0.1$ or $\mathrm{I}^{2}>50 \%$ ) [9]. Publication bias was assessed by visually inspecting a funnel plot [10]. The sensitivity analyses were performed only for ROSC due to the limited number of studies for other outcomes. In the sensitivity analyses for observational studies, the influence of a single study on the overall pooled estimate was evaluated by omitting one study in each step.

\section{Results}

\section{Study identification and selection}

A total of 207 records were identified from the initial database search. We excluded 88 duplicate records and 93 records based on the titles and abstracts. The remaining 26 full-text articles were assessed for eligibility, and 21 were excluded for various reasons (i.e., animal studies or different study content or populations). Finally, 5 studies $[7,11-14]$ were included in the meta-analysis. The selection process is shown in Fig. 1.

\section{Study characteristics}

The main characteristics of the included studies are shown in Table 1. All included studies were observational studies. Among the included studies, there were 2 prospective and 3 retrospective studies. All studies were published in English. Martens et al. reported two databases [12]. All five studies (six cohorts) reported the result of ROSC, two studies [13, 14] reported favorable neurological outcome at discharge or at 30 days after CA, two studies $[11,14]$ reported long term survival, four studies [7, 11, 13, 14] reported initial shockable rhythm.

\section{Quality assessment}

To assess the risk of bias of the cohort studies based on the NOS, 5 studies were rated as a total score of $>7$, indicating a low risk of bias (Table 2).

\section{The primary outcome: ROSC}

The pooled results from the random-effects model combing the RRs for ROSC is shown in Fig. 2. Overall, 9822 patients were included in this analysis (1696 and 8126 in the gasping and control groups, respectively). Gasping was associated with a significant increase of 


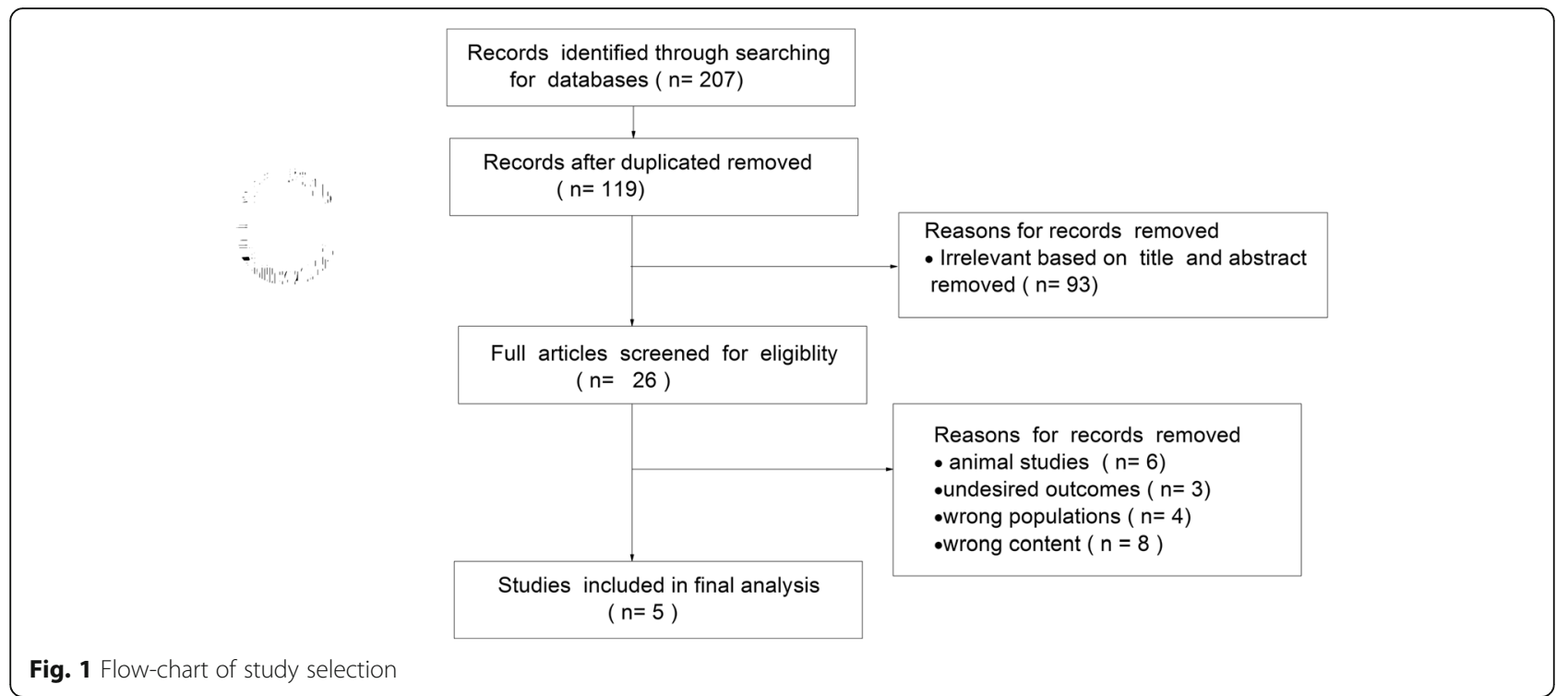

ROSC (RR, 1.87; 95\% CI, 1.64-2.13) with moderate heterogeneity among the studies $\left(\mathrm{I}^{2}=70 \% ; P=0.005\right)$.

\section{The secondary outcomes}

The secondary outcomes are outlined in Fig. 3. Gasping was associated with an increase of favorable neurological outcomes (RR, 3.79; 95\% CI, 1.86-7.73; Fig. 3a), long term survival (RR, 3.46; 95\% CI, 1.70-7.07; Fig. 3b), and initial shockable rhythm (RR, 2.25; 95\% CI, 2.05-2.48; Fig. 3c).

\section{Publication Bias}

For the meta-analysis of gasping on ROSC, there was no evidence of significant publication bias based on the inspection of the funnel plot (Fig. 4a).

\section{Sensitivity analysis}

To further confirm the robustness of the results, we conducted a sensitivity analysis of ROSC, but no significant changes were observed in the outcomes (Fig. 4b).

The results and evidence of heterogeneity were maintained after excluding the studies by Debaty et al. (RR, 1.82; 95\% CI, 1.52-2.18; $\mathrm{I}^{2}=75 \%$ ), Fukushima et al. (RR, 1.87; 95\% CI, 1.60-2.19; $\mathrm{I}^{2}=75 \%$ ), Knorr et al. (RR, 1.81;
95\% CI, 1.57-2.08; $\mathrm{I}^{2}=72 \%$ ), and Martens et al. cohort 1 (RR, 1.84; 95\% CI, 1.56-2.18; $\mathrm{I}^{2}=76 \%$ ) and cohort 2 (RR, 1.82, 95\% CI, 1.55-2.14; $\mathrm{I}^{2}=75 \%$ ). There was also no change in the pooled results after excluding the study by Wolfskeil et al. (RR, 1.97; 95\% CI, 1.85-2.10), but no evidence of heterogeneity was observed among the remaining studies $\left(\mathrm{I}^{2}=0 \%\right)$.

\section{Discussion}

In the present systematic review and meta-analysis, we identified 5 observational studies that were conducted to investigate the prognostic effect of gasping on ROSC and long-term survival in patients with CA. Based on our study analysis, gasping was associated with increased ROSC, which is consistent with previous meta-analysis. In addition, gasping could predict favorable neurological outcomes and long-term survival in patients with OHCA. A high initial shockable rhythm in gasping patients may be one reason for the favorable outcomes.

Gasping is an abnormal breathing pattern which has been defined as an abrupt, sudden and transient inspiratory effort [11]. It is further characterized by short inspiration and expiration and a longer and variable expiratory pause [5].Continued breathing is common

Table1 Characteristics of included studies

\begin{tabular}{|c|c|c|c|c|c|c|c|c|c|c|c|}
\hline Author & Year & Country & Study Design & Age & Location & $\begin{array}{l}\text { Reason of } \\
\text { CA }\end{array}$ & Bystander & Male & Setting & Gasping Time & $\begin{array}{l}\text { Number of } \\
\text { participants }\end{array}$ \\
\hline Martens [12] & 1995 & Belgium & Retrospective & Adult & $\mathrm{OHCA}$ & All & - & $71.7 \%$ & Single center & EMS & 4757 \\
\hline Debaty [14] & 2017 & France & Prospective & Adult & $\mathrm{OHCA}$ & All & $42.43 \%$ & $62.92 \%$ & Multi center & EMS & 1835 \\
\hline Wolfskeil [7] & 2017 & Belgium & Prospective & Adult & $\mathrm{OHCA}$ & All & - & - & Single center & $\begin{array}{l}\text { During } \\
\text { Resuscitation }\end{array}$ & 290 \\
\hline Knor [11] & 2018 & Czece & Retrospective & Adult & $\mathrm{OHCA}$ & Cardiac & $72.94 \%$ & $69.02 \%$ & Single center & EMS & 569 \\
\hline Fukushima [13] & 2017 & Japan & Retrospective & Adult & $\mathrm{OHCA}$ & All & $55.2 \%$ & $65.1 \%$ & Multi center & EMS & 2411 \\
\hline
\end{tabular}


Table 2 Risk of bias assessment of the observational studies

\begin{tabular}{|c|c|c|c|c|c|c|c|c|c|}
\hline \multirow[t]{2}{*}{ Study } & \multicolumn{4}{|l|}{ Selection } & \multirow[t]{2}{*}{ Comparability } & \multicolumn{3}{|l|}{ Outcome } & \multirow{2}{*}{$\begin{array}{l}\text { Total } \\
\text { Score }\end{array}$} \\
\hline & $\begin{array}{l}\text { Exposed } \\
\text { Cohort }\end{array}$ & $\begin{array}{l}\text { Nonexposed } \\
\text { Cohort }\end{array}$ & $\begin{array}{l}\text { Ascertainment of } \\
\text { Exposure }\end{array}$ & $\begin{array}{l}\text { Outcome of } \\
\text { Interest }\end{array}$ & & $\begin{array}{l}\text { Assessment of } \\
\text { Outcome }\end{array}$ & $\begin{array}{l}\text { Length of } \\
\text { Follow-up }\end{array}$ & $\begin{array}{l}\text { Adequacy of } \\
\text { Follow-up }\end{array}$ & \\
\hline Martens &.. & $*$ & * & $*$ & $* *$ & * & * & * & 8 \\
\hline Debaty & * & * & * & * & $* *$ & * & * & * & 9 \\
\hline Wolfskeil & * & * & * & * & * & * & * & * & 8 \\
\hline Knor & $*$ & * & * & * & $* *$ & * & * &. & 9 \\
\hline Fukushima & * & * &. & * & $* *$ & * & * & * & 8 \\
\hline
\end{tabular}

Risk of bias was assessed using the Newcastle-Ottawa Scale. A higher overall score corresponds to a lower risk of bias; a score of $\leq 5$ (out of 9 ) indicates a high risk of bias

during the first minute of $\mathrm{CA}$ induced by ventricular fibrillation (VF) $[4,15]$. In a pig study of breathing activity after the untreated VF, the airflow pattern was similar to that recorded during spontaneous breathing in the first minute; gasping occurred in a crescendo-decrescendo pattern during the second to fifth minute, and all ventilation activity ceased after the sixth minute of untreated VF [16].

OHCA is a leading cause of death and remains a significant public health problem [17]. The reported percentage of gasping ranges from 33 to $60 \%$ in all OHCA patients $[18,19]$. Many animal models have been used to study the physiological mechanisms of gasping. Previous researchers have found that gasping could decrease of intracranial pressure, increase of cerebral perfusion, increase flow of ventilation $[16,20,21]$. The beneficial effect of gasping on circulation and gas exchange during CA has been described [22, 23]. Gasping after CA has been linked to the level of brainstem pO2, arterial baroreceptor and chemoreceptor stimulation following a sudden decrease in blood pressure, and arterial acid-base balance $[14,24]$. Furthermore, initial shockable rhythms in OHCA were correlation with higher survival rates [25]. Since gasping is present only during the first minutes after onset of $\mathrm{CA}$, the non-gasping group might have simply experienced longer ischemia. This assumption is supported by the finding that gasping is more often associated with initial shockable rhythms,which may contribute favorable outcomes.

Although gasping has beneficial effects for CA patients, immediate recognition of gasping is difficult for the bystander [26]. This can prevent or delay recognition of CA. Riou et al. demonstrated that there is potential for improved recognition of agonal breathing if call-takers are trained [27]. Education and training on caller descriptors could turn these obstacles into opportunities to identify OHCA more quickly and comprehensively [13].

For the present meta-analysis, in an attempt to produce robust results, we pre-stated rigorous inclusion criteria and included only studies that clearly stated the outcomes of OHCA patients. Using the previous meta-analysis as a base, we included four other recent studies to assess effects of gasping on ROSC. With the added statistical power of having 9822 cases as opposed to 5066 cases, our meta-analysis suggested that gasping was associated with increased ROSC. Moreover, the sensitivity analysis and exclusion of any single study did not significantly alter the pooled results, which adds robustness to our main finding. In addition, gasping may predict favorable neurological outcomes and long term survival based on our meta-analysis.

In the present study, we observed moderate or high heterogeneity for the short and long outcome results,

\begin{tabular}{|c|c|c|c|c|c|c|c|c|c|}
\hline Study or Subgroup & \multicolumn{2}{|c|}{ Gasping } & \multicolumn{2}{|c|}{ No gasping } & Weight & $\begin{array}{c}\text { Risk Ratio } \\
\text { M-H, Random, 95\% CI }\end{array}$ & \multicolumn{3}{|c|}{$\begin{array}{c}\text { Risk Ratio } \\
\text { M-H, Random, } 95 \% \mathrm{Cl} \\
\end{array}$} \\
\hline Debaty et al 2017 & 150 & 197 & 631 & 1638 & $22.6 \%$ & $1.98[1.79,2.18]$ & & - & \\
\hline Fukushima et al 2017 & 126 & 459 & 296 & 1952 & $17.2 \%$ & $1.81[1.51,2.17]$ & & $\pi$ & \\
\hline Knor et al 2018 & 65 & 135 & 89 & 430 & $13.0 \%$ & $2.33[1.80,3.00]$ & & $\rightarrow$ & \\
\hline Martens et al (1) 1995 & 173 & 516 & 441 & 2519 & $19.4 \%$ & $1.92[1.65,2.22]$ & & - & \\
\hline Martens et al (2)1995 & 140 & 315 & 309 & 1407 & $18.8 \%$ & $2.02[1.73,2.37]$ & & $\pi$ & \\
\hline Wolfskeil et al 2017 & 27 & 74 & 78 & 216 & $9.0 \%$ & $1.01[0.71,1.43]$ & & & \\
\hline Total $(95 \% \mathrm{Cl})$ & & 1696 & & 8162 & $100.0 \%$ & $1.87[1.64,2.13]$ & & $\downarrow$ & \\
\hline Total events & 681 & & 1844 & & & & & & \\
\hline $\begin{array}{l}\text { Heterogeneity: } \mathrm{Tau}^{2}= \\
\text { Test for overall effect: }\end{array}$ & $\begin{array}{l}\text { 02; } \mathrm{Chi}^{2}= \\
=9.44(\mathrm{P}<\end{array}$ & $\begin{array}{l}16.52, \\
<0.000\end{array}$ & $\begin{array}{l}d f=5(P \\
001)\end{array}$ & $=0.005$ & ;); $1^{2}=70 \%$ & & $\begin{array}{lll}0.01 & 0.1 & 1 \\
& \text { Favours [No gasping] }\end{array}$ & $\begin{array}{l}10 \\
\text { Favours [Gasping] }\end{array}$ & 100 \\
\hline
\end{tabular}




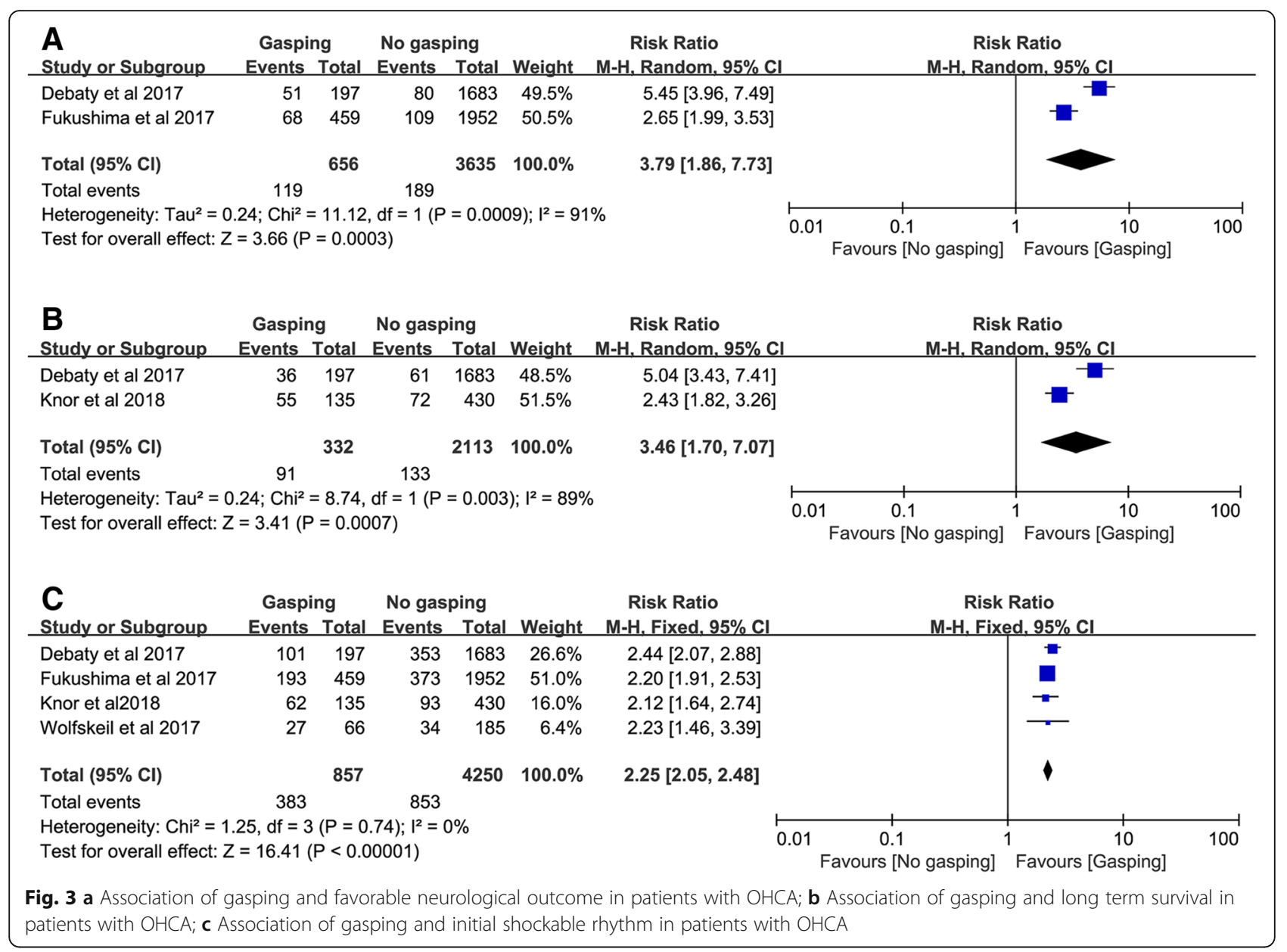

which may be due to the different methods for determining the presence of gasping during CA in these 5 studies.Martens et al. [12] and Knor et al. [11] retrospectively reviewed CPR registries, which leaves their data prone to lacking or incorrect entries. Moreover, the study by Martens et al. [12] included cases from more than 30 years ago. Debaty et al. [14] prospectively collected data during a randomized controlled trial comparing standard CPR to active compression/decompression CPR. Wolfkeil et al. [7] did not demonstrate any association between gasping and ROSC. However, that was a special study, where gasping rate, volume and pressure were measured using a dedicated device. As a consequence: gasping was measured only after endotracheal
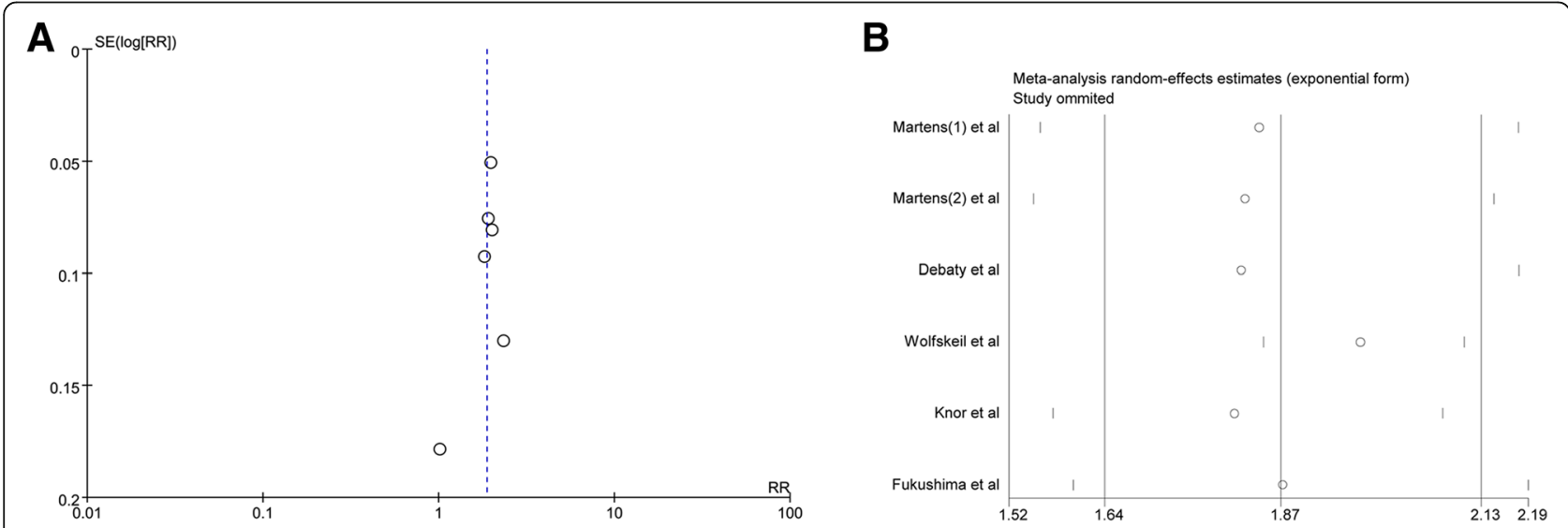

Fig. 4 a Funnel for ROSC in patients with OHCA; b Sensitivity for ROSC in patients with OHCA 
intubation, therefore late on a relatively small patient population and that study may have detected subclinical gasping. Fukushima et al. [13] reviewed audio recordings of emergency callers.

The following points can be considered in further studies. Firstly, there is a need for further education to identify gasping. Secondly, early CPR is crucial for positive CA outcomes, and the use of endotracheal intubation remains debatable in gasping patients. Next, clinical endpoints other than the incidence of gasping, such as gasping volume and gasping rate, should be considered in further studies.

Several potential limitations should be taken into consideration in the present results. Firstly, this finding largely relies on data from observational studies and is potentially subject to selection bias; hence, high-quality and adequately powered studies are warranted. Secondly, other factors that could influence the results, including population characteristics, severity of illness, and reasons for CA, were not considered in the present study. Thirdly, a larger sample size was required to assess the impact of gasping on favorable neurological outcomes and long-term survival. Finally, gasping assessment is a challenging task for rescuer, and the ability to detect gasping can vary among rescuers. Therefore, OHCA patients can be incorrectly assessed as breathing normally.

\section{Conclusion}

Based on the current evidence, gasping could predict short and long outcomes in patients with OHCA. In addition, gasping is associated with a high likelihood of initial shockable rhythm, which may contribute to favorable outcomes.

\section{Acknowledgments \\ None.}

Funding

None.

\section{Availability of data and materials}

All data generated or analyzed during this study are included in this published article.

\section{Authors' contributions}

CS. L and Q. Z had full access to all the data in the study and take responsibility for the integrity of the data and the accuracy of the data analysis. CS. L and Q. Zconceived and designed the study; CS. L, Q. Z, B. L, ZJ. Q led the acquisition, analysis,or interpretation of data; CS. L and Q. Z drafted the manuscript. All authors read and approved the final manuscript.

\section{Ethics approval and consent to participate}

This study did not need ethical approval and consent from any patients involved in the study was also not needed.

\section{Consent for publication}

Not applicable.

\section{Competing interests}

The authors declare they have no competing interests.

\section{Publisher's Note}

Springer Nature remains neutral with regard to jurisdictional claims in published maps and institutional affiliations.

Received: 9 October 2018 Accepted: 29 November 2018

Published online: 14 December 2018

\section{References}

1. Tamhane UU, Chetcuti S, Hameed I, et al. Safety and efficacy of thrombectomy in patients undergoing primary percutaneous coronary intervention for acute ST elevation MI: a meta-analysis of randomized controlled trials [J]. BMC Cardiovasc Disord. 2010;10:10.

2. Haouzi P, Ahmadpour N, Bell HJ, et al. Breathing patterns during cardiac arrest [J]. J Appl Physiol (1985). 2010;109(2):405-11.

3. Soar J, Nolan JP, Bottiger BW, et al. European resuscitation council guidelines for resuscitation 2015: section 3. Adult advanced life support [J]. Resuscitation. 2015;95:100-47.

4. Bobrow BJ, Zuercher M, Ewy GA, et al. Gasping during cardiac arrest in humans is frequent and associated with improved survival []]. Circulation. 2008;118(24):2550-4.

5. Zuercher M, Ewy GA. Gasping during cardiac arrest [J]. Curr Opin Crit Care. 2009;15(3):185-8.

6. Zhao L, Li C, Liu B, et al. The association of gasping and outcome, in out of hospital cardiac arrest: a systematic review and meta-analysis []]. Resuscitation. 2015;97:7-12.

7. Wolfskeil $M$, Vanwulpen $M$, Duchatelet $C$, et al. Detection and quantification of gasping during resuscitation for out-of-hospital cardiac arrest [J]. Resuscitation. 2017;117:40-5.

8. Cook DA, Reed DA. Appraising the quality of medical education research methods: the medical education research study quality instrument and the Newcastle-Ottawa scale-education [J]. Acad Med. 2015;90(8):1067-76.

9. Higgins JP, Thompson SG, Deeks JJ, et al. Measuring inconsistency in meta-analyses [J]. BMJ. 2003;327(7414):557-60.

10. Egger M, Davey SG, Schneider M, et al. Bias in meta-analysis detected by a simple, graphical test [J]. BMJ. 1997;315(7109):629-34.

11. Knor J, Seblova J, Skulec R, et al. The presence of gasping predicts longterm survival in out-of-hospital cardiac arrest patients [J]. Biomed Pap Med Fac Univ Palacky Olomouc Czech Repub. 2018;162(1):32-5.

12. Martens $\mathrm{P}$, Mullie $\mathrm{A}$, Vanhaute $\mathrm{O}$. Clinical status before and during cardiopulmonary resuscitation versus outcome in two consecutive databases. Belgian CPCR study group [J]. Eur J Emerg Med. 1995;2(1):17-23.

13. Fukushima H, Panczyk M, Hu C, et al. Description of Abnormal Breathing Is Associated With Improved Outcomes and Delayed Telephone Cardiopulmonary Resuscitation Instructions [J]. J Am Heart Assoc. 2017;6(9).

14. Debaty G, Labarere J, Frascone RJ, et al. Long-term prognostic value of gasping during out-of-hospital cardiac arrest []]. J Am Coll Cardiol. 2017;70(12):1467-76.

15. Ewy GA, Armstrong PW. A natural biomarker deserving attention: gasping following primary cardiac arrest [J]. J Am Coll Cardiol. 2017;70(12):1477-8.

16. Zuercher M, Ewy GA, Otto CW, et al. Gasping in response to basic resuscitation efforts: observation in a Swine model of cardiac arrest. Crit Care Res Pract. 2010:2010.

17. Zive DM, Schmicker R, Daya M, et al. Survival and variability over time from out of hospital cardiac arrest across large geographically diverse communities participating in the Resuscitation Outcomes Consortium [J]. Resuscitation. 2018;131:74-82.

18. Clark JJ, Larsen MP, Culley LL, et al. Incidence of agonal respirations in sudden cardiac arrest [J]. Ann Emerg Med. 1992;21(12):1464-7.

19. Fukushima $\mathrm{H}$, Imanishi M, Iwami T, et al. Abnormal breathing of sudden cardiac arrest victims described by laypersons and its association with emergency medical service dispatcher-assisted cardiopulmonary resuscitation instruction [J]. Emerg Med J. 2015;32(4):314-7.

20. Srinivasan V, Nadkarni VM, Yannopoulos D, et al. Spontaneous gasping decreases intracranial pressure and improves cerebral perfusion in a pig model of ventricular fibrillation [J]. Resuscitation. 2006;69(2):329-34.

21. Noc M, Weil MH, Tang W, et al. Mechanical ventilation may not be essential for initial cardiopulmonary resuscitation [J]. Chest. 1995;108(3):821-7.

22. Noc M, Weil MH, Sun S, et al. Spontaneous gasping during cardiopulmonary resuscitation without mechanical ventilation [J]. Am J Respir Crit Care Med. 1994;150(3):861-4 
23. Xie J, Weil MH, Sun S, et al. Spontaneous gasping generates cardiac output during cardiac arrest [J]. Crit Care Med. 2004;32(1):238-40.

24. Zuercher M, Ewy GA, Hilwig RW, et al. Continued breathing followed by gasping or apnea in a swine model of ventricular fibrillation cardiac arrest []]. BMC Cardiovasc Disord. 2010;10:36.

25. Wissenberg M, Lippert FK, Folke F, et al. Association of national initiatives to improve cardiac arrest management with rates of bystander intervention and patient survival after out-of-hospital cardiac arrest [J]. JAMA. 2013;310(13):1377-84.

26. Hardeland C, Sunde K, Ramsdal H, et al. Factors impacting upon timely and adequate allocation of prehospital medical assistance and resources to cardiac arrest patients [J]. Resuscitation. 2016;109:56-63.

27. Riou M, Ball S, Williams TA, et al. She's sort of breathing': what linguistic factors determine call-taker recognition of agonal breathing in emergency calls for cardiac arrest? [J]. Resuscitation. 2018;122:92-8.

Ready to submit your research? Choose BMC and benefit from:

- fast, convenient online submission

- thorough peer review by experienced researchers in your field

- rapid publication on acceptance

- support for research data, including large and complex data types

- gold Open Access which fosters wider collaboration and increased citations

- maximum visibility for your research: over $100 \mathrm{M}$ website views per year

At $\mathrm{BMC}$, research is always in progress.

Learn more biomedcentral.com/submissions 